\title{
Authentic Movement: a field of practices Editor's Introduction
}

The aim of this special issue of the Journal for Dance and Somatic Practices, 'Authentic Movement: a field of practices' is to deepen and contribute to the literature currently available and make a contribution to the scoping or defining of the field of practices known as Authentic Movement (AM). The intention is not to limit or prescribe what is or can be done or known but to embrace the many individuals and groups who practice AM and to ask them to give words to their unique contribution to this field. Each person who works with AM does so with specific intentions and theoretical underpinnings; each person or group has unique processes and outcomes. And yet there are surely some attributes of the form we know as AM that are shared. We hope this issue helps to clarify both the differences and similarities in approaches to the practice we call Authentic Movement.

When Mary Starks Whitehouse began asking dancers in her studio to stop dancing and just to all themselves to be moved, she was questioning her early modern dance training. She was clear that she was not looking for a theoretical frame but trying to work out what was happening (Whitehouse, 1979/1999, p.75-6). Perhaps we can say the same about this collection of essays. Each article here gives us a glimpse into a unique articulation of a practice; each article reveals something of the author as much as it reveals the practice of Authentic Movement. Across the globe people say 'I am an Authentic Movement practitioner' but what that is will depend on the person who is practicing and how they learned the practice and from whom. As such these practices operating 
under the rubric of AM are all historically, philosophically, psychologically, spiritually and aesthetically situated.

This issue is not intended to be a thorough historical tracing of the practice, although there is some reference to the history and lineage of AM and we are thrilled to include here articles by leaders in the field: Janet Adler, Joan Chodorow and Tina Stromsted. It is not a thorough examination of all approaches to the practice of AM. This is a selection of articles covering a range of approaches but I would not want the reader to imagine that this is exhaustive in any way. The articles are arranged by loose alphabetical order (mixed with a desire to scatter the visual imagery throughout), rather than by type or other means of definition. It is, I hope, a collection of articles that might help shift the divide between practitioner and academic and help to articulate some of the hidden or invisible aspects of the practice and the language used to articulate that practice. The practitioners have opened their studios and therapy rooms so that the field of AM might be opened up to future practitioners and scholars who are interested to know more about the practice. We hope this issue helps contribute to the examination and articulation of these differences, similarities and distinctions.

In the call for papers for this issue we suggested a possible root system, or historical lineage rather than theoretical underpinning, for AM. In the process of inviting authors to further examine their history so as to deepen our understanding of the implications of AM's development, we have come to think of this lineage and contemporary context as a sort of rhizomatic field or an 
assemblage (Deleuze and Guattari, 1987). The rhizome is a creeping root stalk that sends out roots and shoots as it grows offering an image of AM practices that are multiple, multiplying, complex, different and yet related. We believe that the use of this term offers an image and symbol of our shared history and current practices where both root and shoot emerge, rather than a history which is causal creating root and branch and subsequently source and conclusion. The rhizomatic field allows for founders and newcomers, in a way that we hope honours both, without discounting the lived experience of the practice of AM that invites each person to find out what the practice of AM is and means for them.

The roots of this work, apparent in all three realms of the discipline, are directly known in dance, healing practices and mysticism.

(Adler, 2002, p XVIII).

This early exploration for our lineage and history, introduced by Adler in Offering from the Conscious Body (2002), suggests a 'root system'. This is unique to Adler's work and should not be assumed for the whole field of AM. In a personal communication (2015) Adler asked that we make a distinction between AM more widely and her own approach (The Discipline of Authentic Movement). 'I needed to name the root systems of the discipline as mysticism, healing practices (psychology) and dance'. She is clear that that these words best describe her own journey to develop her own way of practicing, which she now offers as part of a programme called Circles of Four which supports individuals to become teachers of the Discipline of Authentic Movement. Helpfully, Sager (pp.x$\mathrm{x}$ ) attempts to clarify what is unique about Adler's approach and those who work with her in the Circles of Four programme. Sager writes, 
Adler's focus on understanding the experience of duality and unity consciousness in the developing inner witness is one way of distinguishing her work from other important perspectives in the field. She describes the Discipline of Authentic Movement as 'mysteriously, deeply developmental (personal communication).

$$
\text { (Sager, pxx) }
$$

When we published the call for papers on the Authentic Movement Community blog, the host Elizabeth Reid, posted a response and a debate followed about the potential danger of 'defining' the field of AM (we had initially thought this issue would be name Authentic Movement: Defining the Field). Reid writes 'I feel resistance to defining, codifying or even explaining what it is that we do". The aim of the journal issue was not, and is not, to codify or define AM as a singular practice. In the field Authentic Movement there are ever-growing connections and emergences rather than a source root system that confines and restricts the growth of the trunk and branch system of the tree. We believe the idea of a root system has an unconscious bias toward causality, source and conclusion - root, branch and tree. And developing the notion of a field or assemblage suggests that we might embrace many root systems and embrace the notion that there may be more roots. Rather, to re-iterate, the invitation was to offer an opportunity for anyone working with this practice to articulate (in an academic context) the work they do and the theoretical and historical underpinnings in order that we might have a broader, deeper and richer sense of the practices which exist within this assemblage or field. 
Reid goes on to say that on the 2006 version of the Authentic Movement Community website the following statement was offered Authentic Movement can be a discipline unto itself and can be used as a part of many different practices and teachings. Teachers develop the form in their own ways. Practices such as Movement Meditation, Contemplative Dance, Creative Movement Method, or Somatic Psychology use Authentic Movement as part of their training.

http://authenticmovementcommunity.blogspot.co.uk/ (accessed $28 / 09 / 2015)$

I agree. AM might be part of an improvisatory dance practice, used in individual or group psychotherapy or practiced by an individual or teacher who is interested in spiritual (or mystical) approaches to the practice. Also it is important to acknowledge that spiritual experiences may occur in therapy sessions, therapeutic or healing experiences in an AM based improvisation session or variations of all of these might occur at any given moment. My contention is that research into the relationship between the underlying theoretical approaches and rhizomatic connections and emergences will help develop our awareness of the full range and potential of the field of AM.

Reid (above) suggests AM can be a 'discipline unto itself'; Adler calls her practice 'The Discipline of Authentic Movement'. This raises an issue about the use and application of the word 'discipline' - Adler's 'discipline' is a practice in and of itself as defined by Reid but also Reid's quote suggests 'discipline' may refers to any one who is practicing AM for itself rather than as a tool within other 
practices or for other purposes. The word discipline is from the Latin disciplina which means teaching and from discipulus for disciple. Its meanings include 'practice of training people' and 'a branch of knowledge, typically one studied in higher education' (Oxford English Dictionary) revealing a complexity to the use and application of this term. In particular, for this journal and for an academic audience, we are faced with the problematic of a term applied to the practice as developed by Adler (the Discipline of Authentic Movement) and the discipline (or field) of Authentic Movement as a branch (rhizome) of knowledge that we hope to explore and define in more depth but that might contain many varieties, theories, methodologies (such as we might find in the academic discipline/field of English Literature, Dance or Neurobiology). Perhaps what unites the two uses of the term here is that 'discipline' is used in all instances within the broad context of its Latin meaning 'knowledge, instruction, teaching'. In that we are discussing and practising in an arena of knowledge production, instruction, teaching and learning whether we think of those as unique to a particular way of practicing (as in Adler's and Reid's use) or as a way to capture and understand many ways of practicing (as we might use in this journal in its academic sense). For the purposes of clarity, throughout the introduction we will only refer to the 'Discipline' of Authentic Movement if it is the practice offered by Adler or one of her Faculty. In other instances I will refer to Authentic Movement as a specific practice or to the AM 'field' of knowledge production (including knowledge produced in and of practice) as we understand it in academia.

For most the practice of AM consists of noticing, following and then articulating what happens moment by moment for both a mover and a witness. But this 
seemingly simple defining factor is so much more complex in the moment of the practice. Some individuals and groups work with AM as an aid or foundation for dance/performance making and the generation of creative outputs (Allen and Preece, MacMahon, Van Sluizer in this issue) In this example, moving with eyes closed and in the presence of a non-judging witness offers space and time to allow performance or other creative material to emerge that might find its way into the frame of a performance, a poem or some other creative product; or moving might be undertaken within the frame performance much as in improvisation as performance. What is important is that movement emerges and can be part of our creative/dance making practice. For others the practice of AM is a tool or skill that illuminates psychological or symbolic material experientially (Adler, Cahill, Chodorow, Goldhahn, Halstrup, Hartley, Heijland, Stromsted, van Sluizer in this issue). In this practice, moving gives way to speaking about moving in order that we know more about ourselves as human beings in and of the world in which we live. And some AM practitioners use AM as part of a personal practice that supports them in their spiritual journey or development (Stromsted, Adler, Sager, MacMahon in this issue).

Although we may make possible distinctions between the context or environment in which we practice AM (in our psychotherapy practice or in a dance, for example) and the intention we hold when we practice AM, this distinction should not be understood as an attempt to separate mind and body, thinking from sensing, or the sensory-motor experience from our thinking and reasoning. It may not be possible to say that the intention of a practitioner to create a dance piece using AM results only 'dance' material and that no one will 
have transpersonal experiences. It is difficult to imagine that a practitioner offering the practice as a means to explore transpersonal material will never create a performance or a poem from that experience. In all these situations AM is a skill, tool, device or container offered for a purpose but the experiences in the moment of the mover and witness may transcend the original intention. Indeed in AM practice we consider ourselves to be working without intention (which of course is an intention in and of itself).

It is equally difficult to understand and articulate the process of finding words to speak from and as our moving experience because what we 'see' as we move with our eyes closed is not synonymous with the speaking of that experience. We contend that these practices (of moving and speaking) sit alongside one another and give time and space to our capacity to know more about how we (as individuals) are able to articulate that experience. What we experience and how we speak that experience or articulate something from that experience are uniquely connected and we might say differently connected to the process of speaking about an experience. Perhaps it is useful to embrace current research from neuro- and cognitive science to help us understand more fully. As Lakoff and Johnson remind us 'The mind is inherently embodied (1999, p.4) and 'the very structure of reason itself comes from the details of our embodiment' (1999, p. 4).

Each of the authors here write in a style and with an approach that is unique to them and their practice. Adler's 'The Mandorla and the Discipline of Authentic Movement' (pp.x-x) outlines what she is presently calling 'The Discipline of 
Authentic Movement' and uses image to help articulate what she understands as the developmental way in which AM as a ritual discipline evolves. She writes densely and poetically, each word and phrase to be sniffed and savored like fine wine as we seek out and digest its meanings. The article is reprinted here with Adler's kind permission and is also available on her website. ${ }^{1}$ Chodorow's article 'Work in Progress Authentic Movement: Dancing and Moving Active Imagination' (pp.x-x) offers a glimpse into the workshop practice offered by Chodorow and her unique blending of aspects we might recognise from AM but also from Jungian depth psychology and from Dance Movement Psychotherapy. Her work in progress approach aims to help the reader into the unending opening processes that are offered to us in practices such as AM or 'active imagination in movement'. Perhaps we might offer that Chodorow's article is an example of documentation from a practice-as-research project, as it seeks out and the theoretical threads in moments of practice. Those who have read her body of work $^{2}$ will read this article and recognise the theoretical threads that have been a articulated over the course of her career and see how she applies this thinking in her practice as a Dance Movement Therapist and Jungian Analyst. Stromsted's Authentic Movement \& The Evolution of Soul's Body® Work' (p.x-x) is different again in that she begins to articulate some of her understandings of the practices of Janet Adler and Joan Chodorow and how they link with the work of Marion Woodman's 'BodySoul Rhythms'. She does this by weaving a personal thread from her early life through the article. There are also articles by authors who currently work with Adler (Halstrup, Hartley, Cahill, Sager) and those who have previously worked with Adler (Goldhahn, Stromsted) as well as individuals who 
have worked with all three of those teachers plus those who have worked with other individuals and groups across the world.

Stromsted and Chodorow offer a unique perspective on the history of the practice by including Jungian Analyst Tina Keller Jenny in that history. Sager offers an historical context and overview of Janet Adler's developmental perspective on and teaching of the Discipline of Authentic Movement. She examines the development of the 'inner witness' in practitioners of Authentic Movement over a thirty-year span of time. The 'inner witness' might be thought of as an increase in consciousness or a self-reflexive state. It is the ability to be present to oneself, to watch as well as do, to not be merged or 'in' the material that arises but also to be 'with' the movement that we are doing. In this way we are at one and the same time both subject and object to ourselves. Perhaps we might liken this to the currently popular mindfulness practice as a self-help process but we are not watching our thoughts pass us by and sitting with a passive body. We are our body, we notice impulses, thoughts, feelings, senations in our bodies and move with/from/as them. Our moment by moment attention to the here and now of our living, moving/being in the world allows us to expand our sense of who we are as we come to experience ourselves with more depth and clarity.

Sager also offers new researchers a unique methodological approach. Her research methodology is based on phenomenology and suggests the inherent relationship between phenomenology and the practice of AM. 'The methodology of phenomenological research requires a self-aware inquiry into the 
phenomenon of perception, beginning with calling into question the limitations of a single perspective and by 'bracketing' preconceived ideas (Sager, pxx). As Sager goes on to explain 'The practice of the phenomenological researcher is much like the practice of witness consciousness in the Discipline of Authentic Movement. Both require an open receptivity to not know what will happen and a commitment to track one's own inner experience in the presence of another person or an outer phenomenon' (Sager, pxx).

The journal includes two contributions by poets and performers, as artists pages (MacMahon, Van Sluizer, Allen and Preece) and as theoretical papers (Meehan). We offer the artists pages as material to expand the reader's imagination and so they are scattered through the journal in an attempt to prevent the separation and division between theory and practice. In MacMahon’s ‘Holy Dreaming: Poetry and Movement', she writes 'Increasingly there is a sense of a collective participation in an eternal mystery...where the hills, trees, wind, grass and rain seem to participate in the movement' (MacMahon, px). Although the emphasis here is on the poetry, it is clear that the author is wanting to convey something of the mysterious power of moving in the landscape and of the sense of a moving landscape. The concept of mover and witness shifts as we begin to play with the notion of being witnessed by the wind, the mountains, sky as well as other fellow humans. Her poems invoke these experiences. In van Sluizer's 'Art and Poetry in Authentic Movement' we are invited into a 'timelessness' where the boundaries between moving and art making melt away and the space for moving, writing and drawing is offered without the presence of a witness. She also explores the personal theme of aging. 
Another article focusing on artistic practice, or practice as research, is Allen and Preece's 'the moon is my witness'. In this photo documentation and supporting writing, the authors' touch of the role of AM practice in the making and performing of the piece. They ask the question 'how can the authentically moving body, trans-nationally witnessed, become a resonant organ both for sensing ecological relations and writing them into being?' (Allen and Preece, px). Describing the work as Authentic Movement informed durational performance, they tell us that the two artists live on different continents and articulate something of how they 'witnessed' the other via this distance. The photo documentation captures some of this process. It is reminiscent of Sager and Hamlin's Red Thread, Two Women (2006) a beautiful practitioner text that charts the evolution of two movers moving and witnesses across a large distance. Both of these documents are poem and image, an artistic endeavor that documents moments of experience captured in both presence and absence.

Meehan's article is a critique of her practice as research project (and performance) Speak, which developed out of the context of 'debates on embodied practice and language-based articulation' (Meehan, p.x). The PaR project aims to examine the 'relationship between movement and language in Authentic Movement practice' (Meehan, px). Meehan suggests AM develops our 'reflective capacity to articulate experience' as a key or 'focal point of the practice, using body-mind and body-language together'. She goes on to suggest AM 'aims to integrate movement and language, where both are part of the processes of perception and action' (Meehan, px). In a frank and often disarming 
critique of her solo performance and audience feedback she is able to interrogate her keys questions about the role of performance in the practice of AM. Speak relied on a practice of developing set or choreographed movement that had originally emerged in an AM session. She refined and formed that movement so it could be 'performed'. She uses audience feedback as the basis of a critique of her practice, querying whether she was able to be in the present performed moment and why the audience perceived this to be (or not be) the case. She suggests that the practice of AM offers a unique opportunity to find embodied words that speak the experience rather than about the experience (Bacon and Midgelow, 2014, p.15). And as such offers the field of practice as research a unique approach and methodology that might help practitioner-researchers in developing the 'capacity to find language, to become articulate, from within the work' (Bacon and Midgelow, 2014, 15).

Meehan, along with Goldhahn, questions the label 'Authentic Movement'. Meehan suggests that perhaps the term 'Authentic Movement' does maintain 'the assumption of a stable, authentic self that can be derived from movement'. She goes on to propose that, in Authentic Movement practice, movements appear and disappear based on contextual elements, and identities are thus never stable but emerge from evolving personal and environmental relationships' (Meehan, px).

Goldhahn reminds us the term 'authentic' has a lineage from Heidegger into a more contemporary and more problematic use. This is in agreement with Don Hanlon Johnson who, in 2006, wrote that Adler and others in the AM community were using the term 'authenticity' in a manner that was practiced but that links 
to the philosophy of Heidegger and his use of the term 'authenticity' in Being and Time (taken from its Greek origin authentikos meaning original and genuine, acting on one's own authority and self-posited). ${ }^{3}$

My core being is mine to be in one way or another. That core being...is in each case mine... But only in so far as it is essentially something which can be authentic.

(Heidegger in Johnson, 2006, p.6).

Goldhahn suggests we alter the name of the practice to 'moverwitness' as a way of acknowledging what is happening in the practice without implying a judgement on either our everyday way of moving that might be deemed 'inauthentic' or the types of moving we do in the studio that might be judged well or poorly (Goldhahn, pxx).

Goldhahn suggests that the use of the word 'authentic' in the title of the practice is, in itself, off putting for many who are skeptical of authenticity, of the idea that individuals might be or experience themselves as 'authentic' (or not). Goldhahn refers us to the German dance educationalist Artus (1996) who

states that the term 'authentic' attempts to describe the identity-forming aspects of dance and movement in the practice of Authentic Movement. If the term was not already sullied by Heidegger and spoilt by capitalist marketing, authentic could perhaps mean an identity-affirming effect, one in which the individual, through practicing Authentic Movement, affirms and strengthens her ego. (Goldhahn, px) 
She helpfully reminds us that the 'aim of Authentic Movement is not to learn how to be more authentic or how to produce authentic movements. The aim is to learn to be oneself in the presence of others and to be embodied and identified with ones body as a living container of mind and flesh and bones' (Goldhahn, px).

In Mary Starks Whitehouse's seminal essay on her personal journey toward the beginnings of Dance Therapy and its relationship to the work of C. G. Jung, she writes 'When the movement was simple and inevitable, not to be changed no matter how limited or partial, it became what I called 'authentic' - it could be recognised as genuine, belonging to that person' (1999, p.81). As a modern dancer who had become disillusioned with the North American modern dance scene and its ideological perspective, Whitehouse began to question whether the ideological assumption of radical change and freedom so embedded in modern dance in the 1950s and 60s was, in fact, possible. She began searching for meaning in her own life and in the life of the dance. She later called herself a Dance Therapist, but when she began her work there was no such term or profession. She decided to stop calling what she did in the studio with dancers who came to her 'dance' and to call what she did 'movement'. And later began to use the term 'authentic' as a means to explain something about the movement. At that time many others were having similar experiences, for example: Marian Chace, founder of American Dance Therapy; Tina Keller Jenny, Jungian Analyst; Trudi Schoop and Jeri Salkin, Adjunctive Therapy; Charlotte Selver, Sensory Awareness. 
Cahill's 'Blending Authentic Movement and the Internal Family Systems Model' explores case material as a means to help the reader understand more fully how Richard Schwartz's Internal Family Systems (a model for family psychotherapy) and AM work together in a psychotherapeutic setting. She suggests that it is the sense of agency afforded by both IFS and the AM model (as well as other somatic approaches) that is healing. According to psychiatrist and trauma specialist, Bessel van der Kolk "agency is a technical term for the feeling of being in charge of your life: knowing where you stand, knowing that you have a say in what happens to you, knowing that you have some ability to shape your circumstance" (2015, p.95). And this 'agency', according to Cahill (drawing from van der Kolk) is enhanced or sometimes brought to consciousness for the first time through a process van der Kolk refers to as 'interoception'. The interoceptive system is associated with autonomic motor control but is distinct from the (exteroceptive) system that guides somatic motor activity. According to Craig, a neuroanatomist working with pain, this system generates feelings from the body such as 'pain, temperature, itch, sensual touch, muscular and visceral sensations, vasomotor activity, hunger, thirst, and "air hunger"' and seems to be the basis for 'the subjective image of the material self as a feeling (sentient) entity, that is, emotional awareness' (Craig, 2003,p.500).

These body-based feelings, as Jungian Analyst Donald Kalsched reminds us, are the way in which many individuals' bodies 'carry the sequelae of their early trauma in somatic symptoms that bear no obvious relationship to the early injuries' (Kalsched, 2013, p.287). He says for these people, a sense of 'aliveness' is not possible because the past trauma has become encoded in the physiological. 
But, he suggests, there are now methods to work with such states of traumatic dissociation. He mentions the Authentic Movement practitioners and pioneers Joan Chodorow and Tina Stromsted as offering practices of 'active imagination in movement' that aid the processes of working with traumatic dissociation. Although Kalsched does not explore how these movement processes work with trauma, articles by Cahill, Stromsted, Heijland and Hartley begin to bring the potential of body based processes such as Authentic Movement out of the consulting room and into view. From here we can begin to develop our thinking as practitioners as well as researchers. In the example of Cahill, the clinical material gives a detailed focus to the explanation of IFS and AM without over reliance on theoretical justification. This is very much a practitioner writing about what she does in the room; a much needed resource that shifts our perception of the world of AM has one shrouded in mystery. Now the outsider begins to know something of what happens in the studio or consulting room (although this can never be the same as the experience itself). But, as previously mentioned, the mystery is also held in the language which is specifically grounded in the body-based processes and practices being undertaken, but which is often seemingly obtuse or alienating.

Hartley's 'Choice, surrender and transitions in Authentic Movement: Reflections on personal and teaching practice' is an exploration of the inter-relatedness of our everyday practices (in this instance, walking) with AM practice. It is a poignant and personal exploration of the processes of slowing down and opening up to an expansive way of being in the world that sits counter to much that is valued in contemporary society. She writes about a personal transition in her life 
as she moves to live in Norfolk and locates the terms 'choice and surrender' as key themes that have been present in much of her life. It isn't just the geographic transition but also the transition from the use of Authentic Movement as therapeutic practice to spiritual practice.

As we continue and deepen our AM practice, we may begin to notice specific gestures or movement patterns. According to Hartley, we may recognise these movement as repeated openings toward a deepened state of consciousness. This follows Adler, who suggests that often these familiar gestures or movements may hold traumatic material but, in time, may become portals to the transpersonal dimension of practice (Adler 1999, p.185).

Heijland is another author who brings together AM with other psychotherapeutic practices, in this instance Reichian body psychotherapy and mindfulness. The clinical examples help the reader to know more about this practice and descriptions of the principles of the practice are taken from the author's training and experience rather than only theorized. The aim of the practice is to enable clients a free and clear expression of themselves moment by moment. This is a unique contribution to the field as it offers a view into the worlds of both practices and the way in which they can be brought together in clinical practice.

Halstrup extends our understanding of Adler's Discipline of Authentic Movement by incorporating the use of voice into the frame of AM. Her article 'To the Bones and Through, The Discipline of Authentic Movement and Voice Work' gently 
unfolds to suggest that the ritual structures offered by Adler's 'Discipline' can provide a unique and meaningful container for voice work. She is less interested in placing her work in the context of other voice practitioners or music therapists but in beginning to open the fields of AM and therapeutic voice work by explaining how she works, writing 'Often sounding and moving are inseparable, inextricably linked as they unfold together through this precious process that is authentic movement' (Halstrup, px).

The articles in this issue are not placed by links to lineage or type of practice but are arranged so as to give space and time for the reader to engage with material and image as it appears page to page. We hope the reader will read all of the articles but not necessarily sequentially. Such an array of essays from practitioners and academics is, we hope, a unique contribution both to the field of Authentic Movement and to the broader fields of Dance and Somatic Practices. The process of editing the issue has been a rich and rewarding experience. The more we are able to articulate what we are doing in our studios, in a way that is suitable to our practices and our temperament and intention, the richer the field we offer to future generations of practitioners and scholars.

\section{References}

Adler, J.(1999), 'Body and Soul', in ed. Pallaro, P. (1999), Authentic Movement, London \& Philadelphia: Jessica Kingsley Publishers. 
Bacon, J. (2016, forthcoming). 'Authentic Movement as wellbeing practice', in Dance and Movement for Wellbeing: Kaleidoscopic Views of a Diverse Field (eds. Karkou, Oliver and Lycouris), Oxford University Press.

Bacon, Jane and Midgelow, Vida (2014), 'Creative Articulations Process (CAP)', Choreographic Practices 5:1, pp. 7-31.

Craig, A. D. 'Interoception: the sense of the physiological condition of the body'. Current Opinion in Neurobiology. 2003 Aug;13(4):500-5.

Deleuze, G. and Guattari, F. Introduction. A Thousand Plateaus (Minneapolis: University of Minnesota Press. tr. Brian Massumi. pp.3-28. 1987.

Heidegger, Martin. Being and Time. (trans. Stambaugh, J.) New York: State University of New York, 1926/1996.

Johnson, Don Hanlon (2007). The primacy of Experiential Practices in Body Psychotherapy. In Marlock, G. and Weiss, H. (Eds) The Handbook of Body Psychotherapy. Stuttgart: Schattauer GmbH, Verlag für Medizin und Naturwissenschaften and also online, http://donhanlonjohnson.com/newsite/syllabi/primacy,practices-halko.htm (accessed 15/09/2007).

Kalsched, D. (2013).Trauma and the Soul, a psycho-spiritual approach to human development and its interruption. London:Routledge.

Lakoff, G. and Johnson, M. (1999) Philosophy in the Flesh, the embodied mind and its challenge to western thought'. New York: Basic Books.

Pallaro, P. (Ed) (1999). Authentic Movement: Essays by Mary Starks Whitehouse, Janet Adler and Joan Chodorow. London: Jessica Kingsley. 
Pallaro, P. (Ed) (2007). Authentic Movement, Moving the Body, Moving the Self, Being Moved, A collection of essays. Vol.2. London:Jessica Kingsley.

Sager, P. and Hamlin, L. (2006). red thread, two women. Charles Hobson, Pacific Editions Publication.

Van der Kolk, B (2014) The Body Keeps the Score: Brain, Mind, and Body in the Healing of Trauma. New York: Allen Lane Publishers.

Whitehouse, M.S. C.G. 'Jung and Dance Therapy, Two Major Principles'. in Authentic Movement, Pallaro, P. (ed), London \& Philadelphia: Jessica Kingsley. pp.73-101. 1979/1999

\section{Endnotes}

\footnotetext{
${ }^{1}$ www.thedisciplineofauthenticmovement.com

2 for a collection of seminal articles on AM by Joan Chodorow, see Pallaro, P. (Ed) (1999). Authentic Movement: Essays by Mary Starks Whitehouse, Janet Adler and Joan Chodorow. London: Jessica Kingsley. This volume also includes seminal essays by Janet Adler and Mary Starks Whitehouse and should be considered essential reading for anyone interested in the history and development of the practices we now call Authentic Movement.

3 For a more extended discussion on the philosophical implications of Heidegger's notion of authenticity on the practice of AM see Bacon, J. (2016, forthcoming) 'Authentic Movement as well-being practice' Dance and Movement for Wellbeing: Kaleidoscopic Views of a Diverse Field (eds. Karkou, Oliver and Lycouris), Oxford University Press.
} 